\title{
Heterogeneity of breast cancer risk within the South Asian female population in England: a population-based case-control study of first-generation migrants
}

\author{
VA McCormack*,', P Mangtani', D Bhakta', AJ McMichael',2 and I dos Santos Silva' \\ 'Department of Epidemiology and Population Health, London School of Hygiene and Tropical Medicine, London WCIE 7HT, UK
}

\begin{abstract}
South Asian women in England have a lower breast cancer risk than their English-native counterparts, but less is known about variations in risk between distinct South Asian ethnic subgroups. We used the data from a population-based case-control study of first-generation South Asian migrants to assess risks by ethnic subgroup. In all, 240 breast cancer cases, identified through cancer registries, were individually matched on age and general practitioner to two controls. Information on the region of origin, religious and linguistic background, and on breast cancer risk factors was obtained from participants. Breast cancer odds varied significantly between the ethnic subgroups $(P=0.008)$, with risk increasing in the following order: Bangladeshi Muslims (odds ratio (OR) 0.33, 95\% confidence interval (Cl): 0.10, I.06), Punjabi Hindu (OR 0.59, 95\% Cl: 0.33, I.27), Gujarati Hindu (I = reference group), Punjabi Sikh (OR I.23, 95\% Cl: 0.72, 2.I I) and Pakistani/Indian Muslims (OR I.76, 95\% Cl: I. I 0, 2.8I). The statistically significant raised risk in Pakistani/Indian Muslims increased with adjustment for socioeconomic and reproductive risk factors (OR 2. I2, 95\% Cl: I.25, 3.58), but was attenuated, and no longer significant, with further adjustment for waist circumference and intake of nonstarch polysaccharides and fat (OR I.49, 95\% Cl: 0.85, 2.63). These findings reveal differences in breast cancer risk between South Asian ethnic subgroups, which were not fully explained by reproductive differences, but were partly accounted for by diet and body size.

British Journal of Cancer (2004) 90, 160- 166. doi: I 0.1038/sj.bjc.660I 440 www.bjcancer.com
\end{abstract}

(c) 2004 Cancer Research UK

Keywords: breast cancer; South Asian; ethnicity

Breast cancer incidence rates in South Asian women living in England are lower than those in the English native population, but higher than those in the Indian subcontinent (Harding and Rosato, 1999; Winter et al, 1999; Smith et al, 2003), consistent with studies in migrants from low- to high-risk countries in which incidence approaches that of the native population within one or two generations (Shimizu et al, 1991; Ziegler et al, 1993). Although rates are lower than that of the native population, breast cancer remains the most common cancer among South Asian women (Harding and Rosato, 1999; Winter et al, 1999).

Breast cancer rates in this ethnic group, however, reflect the average experience of this diverse population, and thus may conceal important within-population differences in risk. The South Asian population comprises several ethnic subgroups that can vary greatly in terms of culture, religious practices and lifestyle. These variations may lead to differences in the prevalence of breast cancer risk factors and thus in breast cancer risk. Many Gujarati Hindu women, for example, are vegetarians, whereas the majority

*Correspondence: Ms VA McCormack

E-mail: valerie.mccormack@lshtm.ac.uk

${ }^{2}$ Current address: National Centre for Epidemiology and Population Health, The Australian National University, Canberra, Australia

Received 25 July 2003; revised 29 September 2003; accepted 29 September 2003 of Pakistani Muslim women are meat-eaters and the latter, on average, have higher parity. There is also evidence from the Indian subcontinent of variations in risk by religion (Jussawalla et al, 1985) and region (Yeole et al, 1990; Bhurgri et al, 2000; Sen et al, 2002), but, to our knowledge, only one study of mortality has explored whether such differences persist among South Asians in the UK (Balarajan et al, 1984). However, the lack of adequate information on ethnicity in cancer registration data has hampered the examination of incidence rates by ethnic group (Harding and Allen, 1996).

We examined variations in breast cancer risk by ethnic subgroup in a population-based case-control study conducted among first-generation South Asian migrant women in England, and investigated to what extent these variations may be explained by established breast cancer risk factors.

\section{MATERIAL AND METHODS}

The present study is based on data from a case-control study that was designed with the primary aim of investigating the relationship between dietary intake and breast cancer among South Asian migrant women in England (dos Santos Silva et al, 2002). In brief, potential cases were identified from the Thames and West Midlands population-based cancer registries during 1995-99 as women of South Asian ethnic origin with breast cancer diagnosed in the previous 2 years, under age 75 years, and were living at the time 
of the study. For each case, two controls without cancer, matched on date of birth within 5 years, were randomly selected from the South Asian women who were registered with the index case's general practitioner (GP). Women of South Asian ethnicity were identified using a validated name analysis technique (Nanchahal et al, 2001) and were included if they were women born in East Africa or the Indian subcontinent. South Asian ethnicity was later confirmed with their GPs and the participants themselves, who also provided information on the country/region of origin and religious background.

After obtaining permission from the relevant GP, participants were invited to be interviewed at home in English or in their mother tongue, using a structured questionnaire. The women were asked about reproductive factors, including age at menarche, pregnancies, breast-feeding practices and menopausal status. They were considered to be postmenopausal if they had stopped menstruating for at least 6 months. The women were asked about their family history of breast and other cancers, and whether their parents were first-degree relatives. The interviewer also administered a food frequency questionnaire (FFQ), obtaining information about the quantity/portion size and frequency of consumption of 207 food items $2-3$ years previously. The average daily nutrient intake was calculated in CompEat (Nutrition Systems, 1995) using a nutritional database, which included McCance and Widdowson 5th edition (Holland et al, 1995) and its supplements, as well as foods commonly consumed by South Asians in the UK (Judd et al, 2000). The FFQ was validated in a subset of controls using 12monthly 24-h dietary recalls as the reference method, and the percentages of women classified in the same \pm 1 quartile of intake distribution by both methods were $74 \%$ for total energy and 85 , 96 and $90 \%$ for energy-adjusted fat, carbohydrates, protein and NSP, respectively (Sevak et al, in press). At the end of the interview, the women were weighed (to the nearest $0.1 \mathrm{~kg}$ ), and the standing height, sitting height and hip and waist circumferences were measured to the nearest $0.1 \mathrm{~cm}$, using standardised procedures (dos Santos Silva et al, 2002). Levels of physical activity at ages 12 and 30 years were assessed using a series of questions on the duration and frequency of leisure, occupation-related and housework activities. These questions were used to calculate the metabolic equivalent (MET) score per week for each individual (Ainsworth et al, 1993); this corresponds to the energy expenditure per week expressed as multiples of the resting metabolic rate (no. hours $\times$ intensity rate/resting metabolic rate).

We categorised the participants into six relatively homogeneous subgroups according to religion, mother tongue and birth place (both country and province) as follows ( $n=$ number of cases and controls):

(1) Gujarati Hindu ( $n=263)$ : Hindu women born in Gujarat, India (38\%), or born in East Africa, but whose parents came from Gujarat, India (27\%), and Hindu women from other provinces of India (except Punjab) whose mother tongue was Hindi/Gujarati (35\%).

(2) Punjabi Hindu $(n=72)$ : Hindu women born in Punjab, India (58\%), or born in East Africa, but whose parents came from Punjab (13\%) and Hindu women from other Indian provinces whose mother tongue was Punjabi (29\%).

(3) Punjabi Sikh $(n=163)$ : Sikh women whose mother tongue was Punjabi, regardless of the place of birth. In all, $74 \%$ were born in Punjab, $15 \%$ in other provinces of India and $11 \%$ in East Africa.

(4) Pakistani and Indian Muslim ( $n=177)$ : Muslim and Ismaili Muslim women, who were born/lived in Pakistan (60\%), India (19\%) or East Africa (20\%).

(5) Bangladeshi Muslim $(n=35)$ : Muslim women born in Bangladesh.

(6) Other $(n=4)$ : Christian (3) and Buddhist (1) women. Due to small numbers, this group was excluded.

\section{Statistical methods}

Conditional logistic regression models (Breslow and Day, 1980) with each set containing a case and two matched controls, were used to estimate odds ratios (ORs) and 95\% confidence intervals (95\% CI) associated with ethnic subgroup, with the largest group, Gujarati Hindu women, as the reference category. We tested the null hypothesis that the odds of breast cancer was constant across ethnic subgroups by comparing a model with indicators for ethnic subgroup to one without, using a likelihood ratio test (LRT). We then explored whether these associations were confounded firstly by socio-demographic, reproductive and familial breast cancer risk factors, and secondly by other markers of environmental factors. The reproductive factors were categorised as follows: age at menarche $(<13,13,14, \geqslant 15$ years), parity (nulliparous, $1-2,3-4$, $\geqslant 5)$, age at first birth $(<20,20-24,25-29, \geqslant 30$ years, nulliparous), duration of breast feeding (never, $<6,6-11,12-$ $23,24-47, \geqslant 48$ months) and menopausal status (pre- or postmenopausal). Markers of familial risk were family history of breast cancer (yes/no) and parental consanguinity (yes/no). Socioeconomic variables were years of education $(0,1-7,8-13$, $\geqslant 14$ years), social class of household (defined as the higher social class of the participant and, if appropriate, her spouse/partner) and age at migration to the UK. Other markers of environmental exposures (anthropometry, diet and exercise) were treated as continuous variables.

\section{RESULTS}

The study included 240 cases and 477 controls (for three cases it was only possible to obtain one matched control). The response rate for eligible cases that were successfully traced was $79 \%(240$ out of 303). Of the 480 eligible controls initially selected (matched to the 240 cases), $76 \%$ (365 out of 480 ) agreed to participate. For those who refused, replacement controls were selected.

The odds of breast cancer varied significantly between the ethnic subgroups (LRT $P=0.008$ ). Pakistani/Indian Muslim women had a statistically significant 1.88 -fold (95\% CI: 1.19, 2.98) higher odds than Gujarati Hindu women $(P<0.01)$. There was also a reduced risk (by $35 \%, 95 \% \mathrm{CI}:-28 \%, 66 \%$ ) in Punjabi Hindus and an increased risk (by $26 \%, 95 \%$ CI: $-26 \%, 112 \%$ ) in Punjabi Sikhs relative to Gujarati Hindu women, but neither of these associations were statistically significant. We investigated whether these differences were explained by known and potential breast cancer risk factors by examining (i) whether known breast cancer risk factors had associations in the expected direction; (ii) whether the distribution of these risk factors in the controls varied by ethnic subgroup and (iii) whether adjustment for these factors altered the associations of breast cancer with ethnic subgroup.

\section{Associations of known breast cancer risk factors}

The associations of sociodemographic and reproductive variables with breast cancer were as expected (Table 1). Higher socioeconomic status measured either by years of education or nonmanual occupation was positively associated with breast cancer, but there was no association with age at migration to the UK. Later menarche was associated with a lower odds of breast cancer, as was younger age at first pregnancy and higher parity. Having ever breast-fed was associated with a $30 \%$ reduction in risk, which was not confounded by age at first birth or parity, though no association was observed with the total lifetime duration of breastfeeding. Risk was increased in women who had a first-degree relative with this disease, but there was no association with parental consanguinity.

A large waist circumference was statistically significantly associated with risk but MET scores at ages 12 and 30 years, total energy intake, percentage energy from fat or any other macro- 
Table I Breast cancer risk in South Asian first-generation migrants in England by sociodeomographic, reproductive and other variables: univariable analysis

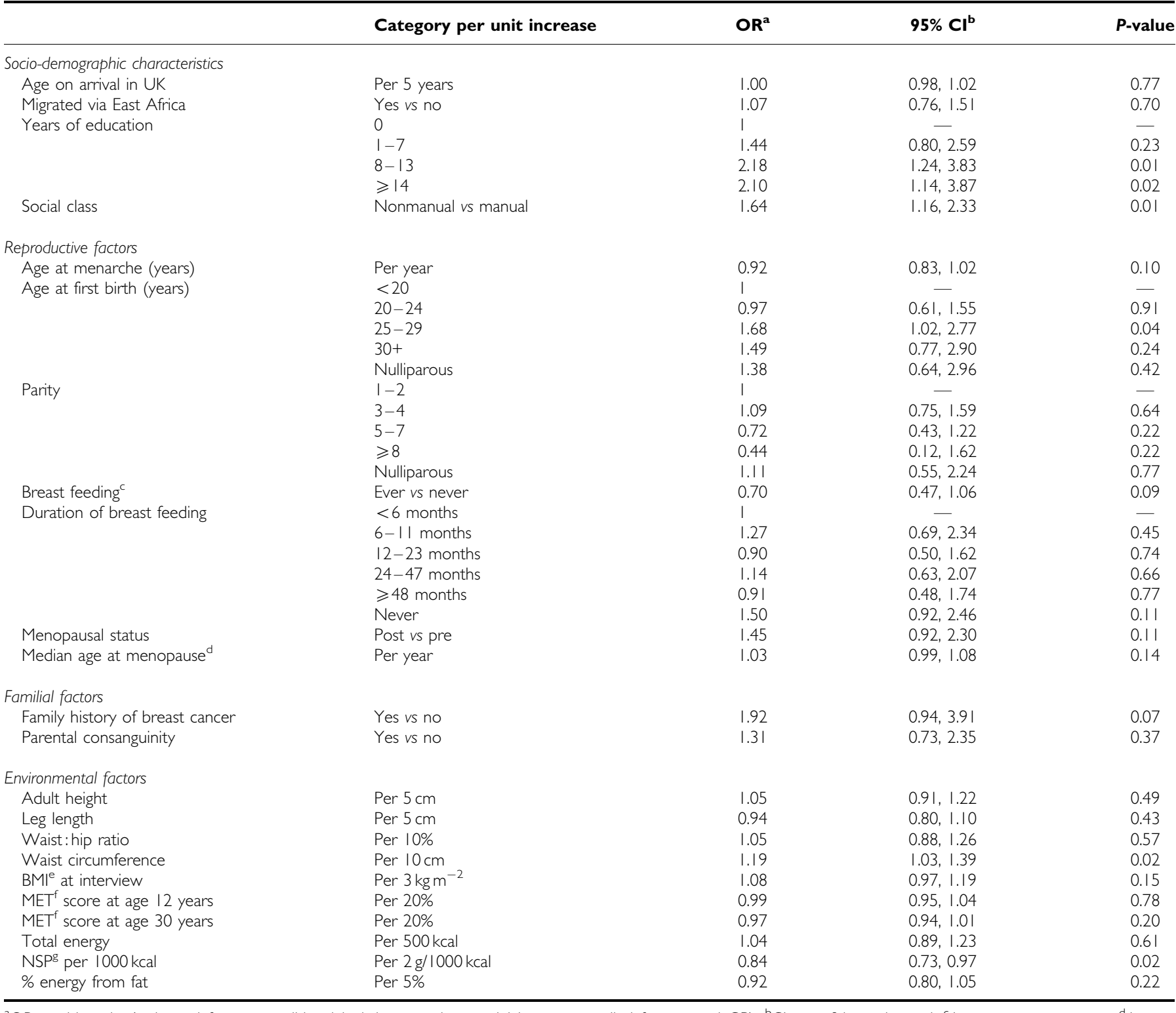

${ }^{\mathrm{a}} \mathrm{OR}=$ odds ratio (estimated from a conditional logistic regression model hence controlled for age and $\mathrm{GP}$ ). ${ }^{\mathrm{b}} \mathrm{Cl}=$ confidence interval. ${ }^{\mathrm{c}} \mathrm{Among}$ parous women. ${ }^{\mathrm{d}} \mathrm{Amon}$ postmenopausal women. ${ }^{\mathrm{B} M \mathrm{MI}}=$ body mass index. $\mathrm{f} \mathrm{MET}=$ metabolic equivalent score per week. ${ }^{\mathrm{g}} \mathrm{NSP}=$ nonstarch polysaccharides.

nutrients, except nonstarch polysaccharides (NSP), were not. Women with diets high in NSP were at a statistically significant reduced risk (OR 0.54 (95\% CI: 0.34, 0.88) comparing the highest to the lowest fourth of energy-adjusted NSP intake).

\section{Distribution of breast cancer risk factors in controls, by the ethnic subgroup}

There were large variations in the distributions of potential risk factors by the ethnic subgroup among the controls (Table 2). The majority $(80 \%)$ of controls migrated to the UK at or after age 20 years, but, on average, Punjabi Sikhs and Punjabi Hindus migrated at younger ages than others, particularly Bangladeshi Muslims. A large proportion $(70 \%)$ of the Gujarati Hindu women migrated from or via East Africa, compared to under $25 \%$ of women in other ethnic subgroups. Gujarati and Punjabi Hindu controls had, on average, better socioeconomic circumstances compared to the other ethnic subgroups. Menarche occurred, on average, latest for
Punjabi Sikh controls. Gujarati Hindu controls had the greatest percentage of nulliparity $(10.2 \%)$, followed by Pakistani/Indian Muslim controls (5.7\%). Among parous controls, the mean age at first birth was earlier in Bangladeshi (22.4 years) and Pakistani/ Indian Muslim women (23.2 years) than in the other groups (23.6 years). The Muslim controls also had, on average, higher parity. Breast feeding was most common and of longest duration among parous Bangladeshi Muslim controls (86\% had breastfed), and least common and of shortest duration in Punjabi Sikh controls $(72 \%)$. The percentage of controls with a family history of breast cancer was similar in all ethnic subgroups (3-5\%), with the exception of the Bangladeshi women (0\%). Approximately $30 \%$ of controls in the two Muslim subgroups, but none in the Hindu and Sikh groups, had consanguineous parents.

The mean height and leg length were similar in Punjabi Hindu, Punjabi Sikh and Pakistani Muslim controls, but considerably lower in Gujarati Hindu controls and particularly so in Bangladeshi Muslim controls. Gujarati Hindu controls also had, on average, 
Table 2 Distribution of breast cancer risk factors in controls by ethnic subgroup

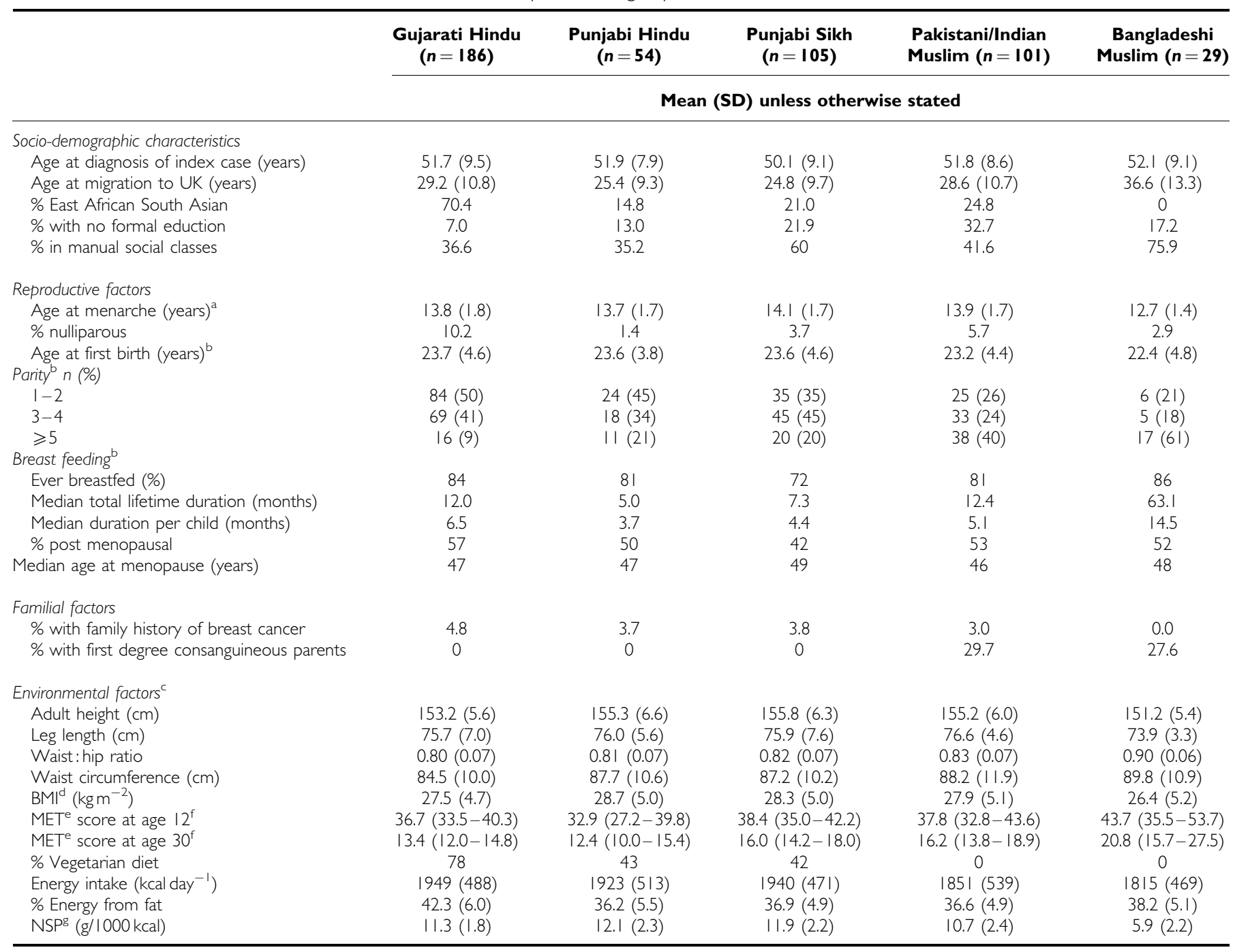

${ }^{\mathrm{a}} 22$ women with missing values excluded. ${ }^{\mathrm{b}}$ Parous women only. ${ }^{\mathrm{C}} \mathrm{All}$ anthropometric data measured at interview; 14 women without anthropometric data excluded. ${ }^{\mathrm{d}} \mathrm{BMI}=$ body mass index. ${ }^{\mathrm{e}} \mathrm{MET}=$ metabolic equivalent score per week. ${ }^{\mathrm{f}}$ Geometric mean and $95 \%$ confidence interval. ${ }^{\mathrm{g}} \mathrm{NSP}=$ nonstarch polysaccarides.

smaller waist circumferences, lower waist: hip ratio and lower BMI. MET scores at ages 12 and 30 years were lowest in Punjabi Hindu women, followed by Gujarati Hindu women, Pakistani/ Indian Muslims, Punjabi Sikhs, and highest in Bangladeshi Muslims. Hindu and Sikh controls had a higher total caloric intake compared to the two Muslim ethnic subgroups. Gujarati Hindu controls, who were predominantly vegetarian, had the highest percentage energy from fat, followed by the Bangladeshi controls and then, with similar percentages, the other three subgroups. NSP intake was highest in Hindus and Sikhs, slightly lower in Pakistani/Indian Muslims and considerably lower in Bangladeshi Muslims.

\section{Breast cancer and ethnic subgroup}

Pakistani/Indian Muslim women had a statistically significant almost two-fold increase in the odds of breast cancer compared to Gujarati Hindu women, despite their more protective reproductive profiles. Greater parity, fewer years in education and an earlier menopause, characteristic of Pakistani/Indian Muslim women (Table 2), are associated with lower risk (Table 1), hence adjusting separately for each of these resulted in higher odds ratios (Table 3 ). Other reproductive and sociodemographic factors did not confound this association, either positively or negatively. Thus, controlling for all the sociodemographic and reproductive factors in Table 3 resulted in an increase in the odds of breast cancer in Pakistani/Indian Muslim women compared to Gujarati Hindus from 1.88 to 2.32 (Table 3 ).

Table 4 shows the effect of adjustment for other environmental factors in the $97 \%$ of women who had complete dietary and anthropometric data. The odds ratio comparing Pakistani/Indian Muslim to Gujarati Hindu women controlled for reproductive factors (OR 2.12, 95\% CI: 1.25, 3.58) was attenuated and became nonsignificant (OR 1.49, 95\% CI: 0.85, 2.63) after further adjustment for waist circumference, NSP and fat intake. Thus, a greater mean waist circumference and especially a lower NSP intake, both of which are associated with an increased risk (Table 1), accounted for most of the increased odds in Pakistani/ Indian Muslims.

Punjabi Sikh women showed a nonsignificant increased risk compared to Gujarati Hindu women (OR 1.26, 95\% CI: 0.74, 2.12). This association was not confounded by reproductive risk factors, but was amplified after controlling for years of education and menopausal status. Controlling for all the risk factors in Table 3, the odds ratio increased from 1.26 to 1.49 (95\% CI: $0.85,2.62)$, but remained nonsignificant. The magnitude of this association 
Table 3 Risk of breast cancer associated with ethnic subgroup, before and after adjustment for reproductive and socio-economic factors

\begin{tabular}{|c|c|c|c|c|c|c|c|c|}
\hline $\begin{array}{l}\text { Ethnic subgroup (cases/controls) } \\
\text { Controlled for age and GP } \\
\text { (through matching) and: }\end{array}$ & $\begin{array}{c}\text { Gujarati Hindu } \\
(80 / 186) \\
\text { OR }^{\mathbf{a}}\end{array}$ & \multicolumn{2}{|c|}{$\begin{array}{l}\text { Punjabi Hindu } \\
\quad(18 / 54)\end{array}$} & \multicolumn{2}{|c|}{$\begin{array}{l}\text { Punjabi Sikh } \\
(58 / 105)\end{array}$} & \multicolumn{2}{|c|}{$\begin{array}{l}\text { Pakistani/Indian } \\
\text { Muslim (76/101) }\end{array}$} & $P$-value ${ }^{c}$ \\
\hline - & I & 0.65 & $0.34,1.28$ & 1.26 & $0.74,2.12$ & 1.88 & $1.19,2.98$ & 0.008 \\
\hline Age at menarche & I & 0.61 & $0.21,1.19$ & 1.29 & $0.76,2.18$ & 1.91 & $1.20,3.04$ & 0.005 \\
\hline Age at first birth & I & 0.66 & $0.33,1.30$ & 1.28 & $0.75,2.17$ & 1.79 & $1.12,2.86$ & 0.017 \\
\hline Family history of breast cancer & I & 0.65 & $0.34,1.28$ & 1.24 & $0.73,2.09$ & 1.90 & $1.20,3.01$ & 0.008 \\
\hline Breast fed ${ }^{d}$ & I & 0.67 & $0.34,1.31$ & 1.21 & $0.71,2.05$ & 1.91 & $1.20,3.04$ & 0.009 \\
\hline Years of formal education ${ }^{\mathrm{e}}$ & I & 0.64 & $0.32,1.26$ & 1.40 & $0.82,2.38$ & 2.21 & $1.37,3.56$ & 0.001 \\
\hline Years since migration to UK & i & 0.65 & $0.33,1.27$ & 1.24 & $0.76,2.10$ & 1.89 & $1.19,2.99$ & 0.008 \\
\hline All of the above & I & 0.74 & $0.36,1.52$ & 1.49 & $0.85,2.62$ & 2.32 & $1.38,3.88$ & 0.003 \\
\hline
\end{tabular}

${ }^{\mathrm{a}} \mathrm{OR}=$ odds ratio, estimated from a conditional logistic regression model. ${ }^{\mathrm{b}} \mathrm{Cl}=$ confidence interval. ${ }^{\mathrm{c}} \mathrm{P}$-value for heterogeneity in odds of breast cancer by ethnic subgroup.

${ }^{d}$ Breast feeding: $0-4.4,4.5-11,12-23,24-47, \geqslant 48$ months, never. ${ }^{e}$ Years of formal education: $0,1-7,8-13, \geqslant 14$ years.

Table 4 Risk of breast cancer associated with ethnic subgroup, before and after adjustment for various environmental factors

\begin{tabular}{|c|c|c|c|c|c|c|c|c|}
\hline \multirow{2}{*}{$\begin{array}{l}\text { Ethnic subgroup } \\
\text { Controlled for age and GP } \\
\text { (through matching) and: }\end{array}$} & \multirow{2}{*}{$\begin{array}{c}\text { Gujarati Hindu } \\
\text { OR }^{\mathbf{a}}\end{array}$} & \multicolumn{2}{|c|}{ Punjabi Hindu } & \multicolumn{2}{|c|}{ Punjabi Sikh } & \multicolumn{2}{|c|}{ Pakistani/Indian Muslim } & \multirow[b]{2}{*}{$P$-value } \\
\hline & & $\mathbf{O R}^{\mathbf{a}}$ & $95 \% \mathrm{Cl}^{\mathrm{b}}$ & $\mathbf{O R}^{\mathbf{a}}$ & $95 \% \mathrm{Cl}^{\mathrm{b}}$ & $\mathbf{O R}^{\mathbf{a}}$ & $95 \% \mathrm{Cl}^{\mathrm{b}}$ & \\
\hline \multicolumn{9}{|l|}{ Anthropometric factors } \\
\hline Adult height (cm) & I & 0.59 & $0.30,1.17$ & 1.22 & $0.71,2.10$ & 1.74 & $1.08,2.80$ & 0.014 \\
\hline Leg length & I & 0.60 & $0.30,1.20$ & 1.25 & $0.73,2.14$ & 1.78 & $1.11,2.87$ & 0.012 \\
\hline $\mathrm{BMI}^{\mathrm{e}}\left(\mathrm{kg} / \mathrm{m}^{2}\right)$ & I & 0.57 & $0.28,1.14$ & 1.21 & $0.70,2.08$ & 1.77 & $1.10,2.86$ & 0.009 \\
\hline \multicolumn{9}{|l|}{ Physical exercise } \\
\hline $\mathrm{MET}^{\mathrm{f}}$ score at age 12 (log) & I & 0.60 & $0.30,1.19$ & 1.24 & $0.72,2.12$ & 1.73 & $1.08,2.78$ & 0.014 \\
\hline MET $^{f}$ score at age 30 (log) & I & 0.57 & $0.28,1.17$ & 1.24 & $0.72,2.13$ & 1.71 & $1.06,2.78$ & 0.017 \\
\hline \multicolumn{9}{|l|}{ Dietary factors } \\
\hline Table 3 factors, NSPg & I & 0.78 & $0.37,1.64$ & 1.57 & $0.88,2.82$ & 1.82 & $1.06,3.12$ & 0.048 \\
\hline Table 3 factors, NSP', fat & I & 0.66 & $0.30,1.44$ & 1.39 & $0.76,2.54$ & 1.63 & $0.94,2.85$ & 0.079 \\
\hline Table 3 factors, NSP', fat, waist circumference & । & 0.62 & $0.28,1.36$ & 1.32 & $0.72,2.42$ & 1.49 & $0.85,2.63$ & 0.118 \\
\hline
\end{tabular}

${ }^{a} \mathrm{OR}=$ odds ratio, estimated from a conditional logistic regression model. ${ }^{\mathrm{b}} \mathrm{Cl}=$ confidence interval. ${ }^{\mathrm{c}} \mathrm{P}$-value for heterogeneity in odds of breast cancer by ethnic subgroup. ${ }^{\mathrm{d}}$ These ORs are slightly different from those in Table 3 because the analysis in Table 4 is restricted to $97 \%$ of women who had complete dietary and anthropometric data. ${ }^{\mathrm{e}} \mathrm{BMI}=$ body mass index. ${ }^{\mathrm{f}} \mathrm{MET}=$ metabolic equivalent score per week. ${ }^{\mathrm{g}} \mathrm{NSP}=$ nonstarch polysaccharides.

increased further after taking the protective effect of a high mean NSP intake into account, but this was counterbalanced by the adverse effect of a larger waist circumference. Thus, the odds ratio adjusted for reproductive factors, waist circumference, NSP and fat intake was 1.32 (95\% CI: 0.72, 2.42).

By contrast, Punjabi Hindu women had a nonsignificant $35 \%$ reduction in the odds of breast cancer compared to Gujarati Hindu women, although the confidence interval is very wide due to only 18 cases. The magnitude of this reduction decreased slightly with adjustment for the reproductive and socioeconomic factors in Table 3, but resumed its original level after further adjustment for NSP and fat intake and waist circumference (Table 4).

The univariable analysis showed that Bangladeshi women were at a much reduced odds compared to all other ethnic subgroups (OR 0.33 (95\% CI: 0.10, 1.06) compared to Gujarati Hindu women). This reduction is possibly driven by their lower mean age at first birth, higher parity and longer lifetime duration of breast-feeding (Table 2), but as this subgroup consisted of only six cases and 29 controls, no further analyses were possible.

\section{DISCUSSION}

We endeavoured to obtain a representative sample of the South Asian population in England by using population-based controls, the ethnic distribution of which was similar to that expected according to the 1991 Census. The observed/expected percentage of controls by ethnic subgroup was $77 \% / 78 \%, 18 \% / 14 \%$ and $6 \% /$ $9 \%$ for Indians, Pakistanis and Bangladeshis, respectively (dos Santos Silva et al, 2002). Risk factor distributions in controls were also similar to that in Census and Health Survey data. For example, that a higher percentage of Pakistanis $(45 \%)$ compared to Indians 
(31\%) had no qualifications in the 2001 census (Office for National Statistics, 2003) is consistent with our findings for educational attainment. Face-to-face interviews with each participant should have resulted in minimal misclassification of ethnic subgroup. By matching on GP, we may have made controls similar to cases with respect to ethnic subgroup, as first-generation migrants from the same region of origin often settle in particular areas, but this would have led to an attenuation of the results and so would not explain our findings.

We found great heterogeneity in breast cancer risk between South Asian ethnic subgroups, with risk increasing in the following order: Bangladeshi Muslims $(\mathrm{OR}=0.33)$, Punjabi Hindu (0.65), Gujarati Hindu ( $1=$ reference group), Punjabi Sikh (1.26) and Pakistani/Indian Muslims (1.88).

Pakistani/Indian Muslims were the only group with a statistically significant increased risk compared to Gujarati Hindu women. Their increased risk is consistent with a study of all deaths in 1975-77 in England and Wales, in which proportional mortality ratios were much higher in Muslims compared to Gujarati and Punjabi South Asian female immigrants (Balarajan et al, 1984). Additionally, similar associations were found in Greater Bombay in 1973-78 where breast cancer incidence rates were highest among Parsi women, followed by Christian, Muslim and then Hindu women (Jussawalla et al, 1985). Breast cancer incidence rates reported by cancer registries in the Indian subcontinent also suggest higher rates in Pakistani women, being 51.7 per 100000 women in 1995-97 in Karachi, Pakistani (Bhurgri et al, 2000) compared to 24.9 and 25.1 in the Indian cities of Bombay in 1985 (Yeole et al, 1990) and Calcutta in 1998-99 (Sen et al, 2002), respectively. This study therefore suggests that the ranking of risk among South Asians in the UK remains the same as that in the subcontinent, despite higher overall incidence rates in the UK (Winter et al, 1999).

The major benefit of this study is the opportunity to investigate factors that might account for the differences in risk. Reproductive factors have previously been shown to have similar associations in low- and high-risk areas (Rao et al, 1994), as was the case in the present study. However, although having breastfed was protective, the lack of association with the duration of breast feeding is contrary to the finding of a large pooled analysis (Collaborative Group on Hormonal Factors in Breast Cancer, 2002) and may be due to nondifferential recall bias. A high intake of NSP was associated with lower breast cancer risk, as we previously reported (dos Santos Silva et al, 2002). The increased risk associated with a large waist circumference is consistent with findings from other studies (Huang et al, 1999; Friedenreich et al, 2002). Waist circumference was, however, measured after diagnosis for cases so may have been affected by the disease and/or its treatment (i.e. by chemotherapy (Aslani et al, 1999)), but when analyses were restricted to women who reported not having changed weight in the past 2-3 years, this association strengthened further. We could not explain the lack of association of adult height with breast cancer by too homogeneous a height distribution, as the interquartile range $(139-169 \mathrm{~cm})$ was as wide as that in studies that have found an association (van den Brandt et al, 1997). Rates of consanguineous marriages in parents of Pakistani/Indian Muslim controls (30\%) were similar to those observed in Pakistan (Bittles et al, 1993), but this factor was not related to breast cancer in this study.

The almost two-fold greater risk of breast cancer in Pakistani/ Indian Muslims than in Gujarati Hindus is somewhat surprising given their larger family sizes, earlier age at first birth and longer duration of breast feeding; thus, taking these factors into account widened the difference further. This association was unexplained by markers of genetic influences such as family history of breast cancer or parental consanguinity.

These findings seem to indicate that much of the difference in risk is due to lifestyle/environmental factors other than reproduc- tive behaviour. Firstly, a lower intake of NSP in Pakistani/Indian Muslim women compared to Gujarati Hindu women accounted for much of the increased risk. Pakistani women tend to be meateaters, whereas most Hindus and many Sikhs are lacto-vegetarians. Gujarati Hindu controls consumed more vegetable dishes (mean $347 \mathrm{~g} \mathrm{day}^{-1}$ ), more pulse/lentil/dhal dishes (103.2 $\mathrm{g} \mathrm{day}^{-1}$ ) and more fruit (1.8 servings day $\left.{ }^{-1}\right)$ compared to Pakistani/Indian Muslim women (with corresponding intakes of $256,40.7 \mathrm{~g} \mathrm{day}^{-1}$ and 1.6 servings day $^{-1}$, respectively), resulting in their higher NSP intake. These intakes are consistent with a survey in pregnant women (Wharton et al, 1984) and with the Health Survey for England (2001), in which, for example, $28 \%$ of Indian women consumed vegetables at least six times per week, compared to $11 \%$ of Pakistani women. Greater differences in fibre intake exist in the Indian subcontinent (FAO, 1982); therefore, these groups may have had even greater differences in NSP intake before migration and, in particular, during childhood, a period of aetiological importance for breast cancer (Hilakivi-Clarke et al, 2001). Secondly, a larger waist circumference (by $3.7 \mathrm{~cm}$ compared to Gujarati Hindu controls (standard error $1.3 \mathrm{~cm}$ )) also contributed to their increased risk. This possibly reflects their more sedentary lifestyles, as only $28 \%$ of Pakistani/Indian Muslim controls had worked outside the home in the 10 years prior to interview, whereas two-thirds of Hindu and Sikh women had. The Health Survey in England (2001) also found lower levels of physical activity in Pakistani women, for exmaple, $72 \%$ of Pakistanis compared to $39 \%$ of Indian women aged 55 years and over had not participated in any form of moderate/vigorous activity in the last 4 weeks. However, MET scores based on recall of activities at ages 12 and 30 years were not related to breast cancer in this study and did not differ across the ethnic subgroups.

Punjabi Sikh women, the second largest Indian ethnic subgroup in the UK, were at an increased, although nonsignificant, risk of breast cancer compared to Gujarati Hindu women, after adjusting for known risk factors. In contrast, Punjabi Hindu and Bangladeshi Muslim women had a lower (nonsignificant) risk relative to Gujarati Hindu women. The distinct characteristics of the Bangladeshi Muslim subgroup, such as a fish-based diet, short stature and favourable reproductive profile, may influence breast cancer risk and will make this an interesting group to study in future years as more of this population reaches the ages when breast cancer risk is highest.

In summary, this study reveals that breast cancer rates for South Asian women in England mask great heterogeneity in risk within this diverse ethnic group. Pakistani/Indian Muslim women were at the highest risk compared to all other South Asian ethnic subgroups - an association that appears to be related to differences in diet and body size. These findings may be of use when considering the low uptake of breast screening in South Asian women (Hoare, 1996). They suggest that characterising all South Asians, regardless of their ethnic subgroup, as having a 'low risk' of breast cancer relative to non-South Asians may be misleading, particularly in light of recent findings showing that breast cancer incidence is rising faster among South Asians in England than among non-South Asians (Smith et al, 2003). This study highlights the need for further research on breast cancer within the South Asian population and, in particular, the need for estimation of absolute incidence risks by ethnic subgroup.

\section{ACKNOWLEDGEMENTS}

We thank all the women who participated in this study. Nidhi Khurana, Rakhi Kabawala, Bonita Peachey and Ha Nguyen for their administrative support; Leena Sevak for carrying out dietary interviews and providing nutritional advice; Tashmin Kassam- 
Khamis for access to her South Asian nutrient database; staff of the Thames and West Midlands Cancer Registries for help with the identification of breast cancer cases and staff of health authorities and general practitioners for enabling us to identify potential controls. This study was funded by the Cancer Research Campaign (now Cancer Research UK), grant number SP2315.

\section{REFERENCES}

Ainsworth BE, Haskell WL, Leon AS, Jacobs Jr DR, Montoye HJ, Sallis JF, Paffenbarger Jr RS (1993) Compendium of physical activities: classification of energy costs of human physical activities. Med Sci Sports Exerc 25: $71-80$

Aslani A, Smith RC, Allen BJ, Pavlakis N, Levi JA (1999) Changes in body composition during breast cancer chemotherapy with the CMF-regimen. Breast Cancer Res Treat 57: 285 - 290

Balarajan R, Bulusu L, Adelstein AM, Shukla V (1984) Patterns of mortality among migrants to England and Wales from the Indian subcontinent. $\mathrm{Br}$ Med J 289: $1185-1187$

Bhurgri Y, Bhurgri A, Hassan SH, Zaidi SHM, Rahim A, Sankaranarayanan R, Parkin DM (2000) Cancer incidence in Karachi, Pakistan: first results from Karachi Cancer registry. Int J Cancer 85: 325-329

Bittles AH, Grant JC, Shami SA (1993) Consanguinity as a determinant of reproductive behaviour and mortality in Pakistan. Int J Epidemiol 22: $463-467$

Breslow NE, Day NE (1980) Statistical Methods in Cancer Research: Volume 1 - The Analysis of Case-Control Studies. Lyon: ARC Scientific Publications No. 32

Collaborative Group on Hormonal Factors in Breast Cancer (2002) Breast cancer and breastfeeding: collaborative reanalysis of individual data from 47 epidemiological studies in 30 countries, including 50302 women with breast cancer and 96973 women without the disease. Lancet 360: $187-195$

dos Santos Silva I, Mangtani P, McCormack V, Bhakta D, Sevak L, McMichael AJ (2002) Lifelong vegetarianism and risk of breast cancer: a population-cased case-control study among South Asian migrant women living in England. Int J Cancer 99: 238-244

Food and Agriculture Organization (FAO) (1982) Legumes in Human Nutrition. FAO Food and Nutrition Paper 20. Rome: Food and Agriculture Organziation of the United Nations

Friedenreich CM, Courneya KS, Bryant HE (2002) Case-control study of anthropometric measures and breast cancer risk. Int J Cancer 99: 445 452

Harding S, Allen EJ (1996) Sources and uses of data on cancer among ethnic subgroups. Br J Cancer 74(Suppl 29): S17-S21

Harding S, Rosato M (1999) Cancer incidence among first generation Scottish, Irish, West Indian and South Asian migrants living in England and Wales. Ethnicity Health 4(1-2): 83-92

Health Survey for England (2001) The Health of Minority Ethnic subgroups 1999 Volume 1: Findings. London: The Stationary Office

Hilakivi-Clarke L, Forsen T, Eriksson JG, Luoto R, Tuomilehto J, Osmond D, Barker DJ (2001) Tallness and overweight during childhood have opposing effects on breast cancer risk. Br J Cancer 85: 1680-1684

Hoare T (1996) Breast screening and ethnic minorities. Br J Cancer 74(Suppl 29): S38-S41

Holland B, Welch AA, Unwin ID, Paul AA, Southgate DAT (1995) McCance and Widdowson's the composition of foods, 5th ed. Cambridge: Royal Society of Chemistry
Huang Z, Willett WC, Colditz GA, Hunter DJ, Manson JE, Rosner B, Speizer FE, Hankinson SE (1999) Waist circumference, waist: hip ratio, and risk of breast cancer in the Nurses' Health Study. Am J Epidemiol 150: $1316-$ 1324

Judd PA, Kassam-Khamis T, Thomas JE (2000) The Composition and Nutrient Content of Foods Commonly Consumed by South Asians in the UK. London: The Agha Khan Health Board

Jussawalla DJ, Yeole BB, Natekar MV (1985) Cancer in Indian Moslems. Cancer 55: $1149-1158$

Nanchahal K, Mangtani P, Alston M, dos Santos Silva I (2001) Development and validation of a South Asian Names and Group Recognition Algorithm (SANGRA) for use in British health-related datasets. J Publ Health Med 23: 278-285

Nutrition Systems (1995) CompEat, version 5. London: Carlson Bengston Consultants Limited

Office for National Statistics (2003) Census 2001 National Report for England and Wales National Statistics. London: The Stationary Office

Rao DN, Ganesh B, Desai PB (1994) Role of reproductive factors in breast cancer in a low-risk area: a case-control study. Br J Cancer 70: 129-132

Sen U, Sankaranarayanan R, Mandal S, Ramanakumar AV, Parkin DM, Siddiqi M (2002) Cancer patterns in eastern India: the first report of the Kolkata cancer registry. Int J Cancer 100: 86-91

Sevak L, Mangtani P, Bhakta D, McCormack VA, dos Santos Silva I (in press) Validation of a food frequency questionnaire to assess macro- and micro-nutrient intake among South Asians in the United Kingdom. Eur J Nutr

Shimizu H, Ross RK, Bernstein L, Yatani R, Henderson BE, Mack TM (1991) Cancers of the prostate and breast among Japanese and white immigrants in Los Angeles County. Br J Cancer 63: $963-966$

Smith LK, Botha JL, Benghiat A, Steward WP (2003) Latest trends in cancer incidence among UK South Asians in Leicester. $\mathrm{Br}$ J Cancer 89: $70-73$

van den Brandt PA, Dirx MJ, Ronckers CM, van den Hoogen P, Goldbohm RA (1997) Height, weight, weight change, and postmenopausal breast cancer risk: The Netherlands Cohort Study. Cancer Causes Control 8: 38 47

Wharton PA, Eaton PM, Wharton BA (1984) Subethnic variation in the diets of Moslem, Sikh and Hindu pregnant women at Sorrento Maternity Hospital, Birmingham. Br J Nutr 52: 469-476

Winter H, Cheng KK, Cummins C, Maric R, Silcocks P, Varghese C (1999) Cancer incidence in the South Asian population of England (1990-92). Br J Cancer 79: 645-654

Yeole BB, Jayant K, Jussawalla DJ (1990) Trends in breast cancer incidence in greater Bombay: an epidemiological assessment. Bull World Health Organ 68: $245-249$

Ziegler RG, Hoover RN, Pike MC, Hildesheim A, Nomura AM, West DW, Wu-Williams AH, Kolonel LN, Horn-Ross PL, Rosenthal JF (1993) Migration patterns and breast cancer risk in Asian-American women. $J$ Natl Cancer Inst 85: 1819-1827 